\title{
A preliminary report of experimental and clinical observations upon cervical carotid artery blood flow
}

\author{
W. EUGENE STERN \\ From the Department of Surgery/Neurosurgery, University of California \\ Medical Center, Los Angeles, U.S.A.
}

A technical advance which illuminates further the dynamics of blood supply to and within the intracranial chamber should be welcomed by the neurological surgeon. The adaptation of the principle of the electromagnetic monitoring of blood flow into a practical tool as described by Kolin (1936) provides such an advance, for it permits the measuring of blood flow through an unopened artery.

This paper presents observations made on the influence of certain commonly employed surgical manoeuvres upon arterial flow through cervical carotid arteries, utilizing, simultaneously, two electromagnetic flow meters of a design recently described by Westersten, Herrold, and Assali (1960).

\section{METHODS}

The data were collected from one dog, one cat, four monkeys, and two patients. In the animal studies anaesthesia was induced with intravenous pentobarbital sodium, $30 \mathrm{mg} . / \mathrm{kg}$. A tracheal cannula was inserted when required to maintain a patent airway, and a plastic flowprobe collar of 2 to $3 \mathrm{~mm}$. vessel-diameter capacity was inserted about each common carotid artery in the neck. The snug fit of the flowmeter collar about the vessel ensured a constant vessel diameter throughout the observations. The strength of the magnetic field from the electrically energized magnet in the probe-collar was maintained constant. Each probe was calibrated in vitro by establishing the relationship between the voltage induced from an electrolyte solution flowing through a segment of excised artery and the volume of flow as actually measured into a graduated cylinder. A linear relationship between volume of flow per unit time and voltage was readily established and coincided with the similar relationship reported by Richards and Williams (1953). It was thus possible to equate the voltage induced with flow expressed in millilitres per minute. The electrical circuits of the meters utilized are described by Westersten et al. (1960), and the pulsatile and integrated flow curves presented were produced on an Offner ink-writing polygraph. Femoral arterial blood pressure and cerebrospinal fluid pressures were recorded on a Sanborn dual-channel unit from Statham transducers.

The procedures employed in the two patients are described in greater detail in the case presentations. Modified instrumentation was used and the recordings were made onto a Sanborn heated stylus recorder from the internal carotid arteries.

The vertebral arteries in three of the monkeys studied were ligated at their origins before the carotid recordings. The mechanical influences studied were cervical carotid artery occlusion and aortic arch occlusion distal to the origin of the left subclavian artery.

The anatomy of the circle of Willis was studied in the brains of three animals by a dissection of the injected specimens and indirectly in the two patients under treatment by cerebral angiography.

The cerebrospinal fluid pressures recorded from the

TABLE I

COMMON CAROTID FLOW IN ANIMALS ${ }^{1}$

\begin{tabular}{|c|c|c|c|}
\hline Animal & $\begin{array}{l}\text { Left Common Carotid Flow } \\
(\mathrm{ml} / \mathrm{/min} .)\end{array}$ & $\begin{array}{l}\text { Right Common Carotid Flow } \\
\text { (ml./min.) }\end{array}$ & $\begin{array}{l}\text { Combined Carotid Flow } \\
(\mathrm{ml} . / \mathrm{min} .)\end{array}$ \\
\hline Monkey BF 1 without vertebral ligation & $\begin{array}{l}19 \\
18 \\
21 \\
19\end{array}$ & $\begin{array}{l}27 \\
41 \\
50 \\
47\end{array}$ & $\begin{array}{l}46 \\
59 \\
71 \\
66\end{array}$ \\
\hline Monkey BF 3 after vertebral ligation & $\begin{array}{l}43 \\
48\end{array}$ & $\begin{array}{l}46 \\
43\end{array}$ & $\begin{array}{l}89 \\
92\end{array}$ \\
\hline $\begin{array}{l}\text { Monkey BF } 4 \text { after vertebral ligation } \\
\text { Monkey BF } 6 \text { after vertebral ligation } \\
\text { Dog BF } 2 \text { without vertebral ligation }\end{array}$ & $\begin{array}{l}28 \\
61 \\
94\end{array}$ & $\begin{array}{l}19 \\
53 \\
82\end{array}$ & $\begin{array}{r}47 \\
114 \\
176\end{array}$ \\
\hline
\end{tabular}

${ }^{1}$ The integrated values were sampled from stable sections of a continuous tracing. 
cisterna magna were made so as to reveal changes in cerebrospinal fluid pulse variations rather than absolute pressure values. The tracings therefore are uncalibrated.

\section{RESULTS IN THE ANIMAL SERIES}

The data collected are best presented in the accompanying figures which indicate the pattern of flow, the corresponding values for flow in millilitres per minute, and the response of flow to mechanical occlusion of the carotid and aortic vessels. The data are conveniently expressed as mean or integrated values. Representative values for flow taken from continuous records of the dog and each of the monkeys studied are tabulated in Table I. The variability from animal to animal and between the two carotid arteries in the same animal is notable.

CAROTID OCCLUSION With the exception of one monkey, in all animals (four monkeys, one dog, and one cat) there was observed to be an increase in common carotid arterial flow with mechanical occlusion of the opposite artery irrespective of which of the two arteries was occluded. Figure 1 illustrates this response in the dog and Fig. 2 in the monkey. The figures reveal the degree to which flow is enhanced in the animal under study. The rise noted was again variable from animal to animal but reached maximum values equivalent to $85 \%$ of the combined pre-occlusion carotid flow. Table II presents the integrated values from one monkey undergoing carotid occlusion and includes the femoral arterial pressure responses accompanying carotid occlusion.

\section{TABLE II}

EFFECTS OF UNILATERAL COMMON CAROTID ARTERY OCCLUSION (BF 3 MONKEY)

\begin{tabular}{lccc} 
& $\begin{array}{l}\text { Left Carotid } \\
\text { Flow } \\
(\text { ml./min. })\end{array}$ & $\begin{array}{l}\text { Right } \text { Carotid } \\
\text { Flow } \\
(\text { ml. } / \text { min. })\end{array}$ & $\begin{array}{l}\text { Femoral Blood } \\
\text { Pressure } \\
(\text { mm. } \text { Hg })\end{array}$ \\
\hline Before occlusion & 45 & 59 & $192 / 118$ \\
During occlusion & 88 & 0 & $222 / 140$ \\
After occlusion & 49 & 42 & $200 / 126$
\end{tabular}

The contralateral increase in flow with ipsilateral common carotid artery occlusion which was observed repeatedly in five animals was a phenomenon initially noted in acute experiments only. To test whether such a rise would be sustained a chronic preparation was used.

In an $8 \frac{1}{2} \mathrm{~kg}$. monkey (BF 6) bilateral carotid flow data were collected. Unilateral occlusion of either artery resulted in a prompt increase in flow in the contralateral vessel. The two vertebral arteries were

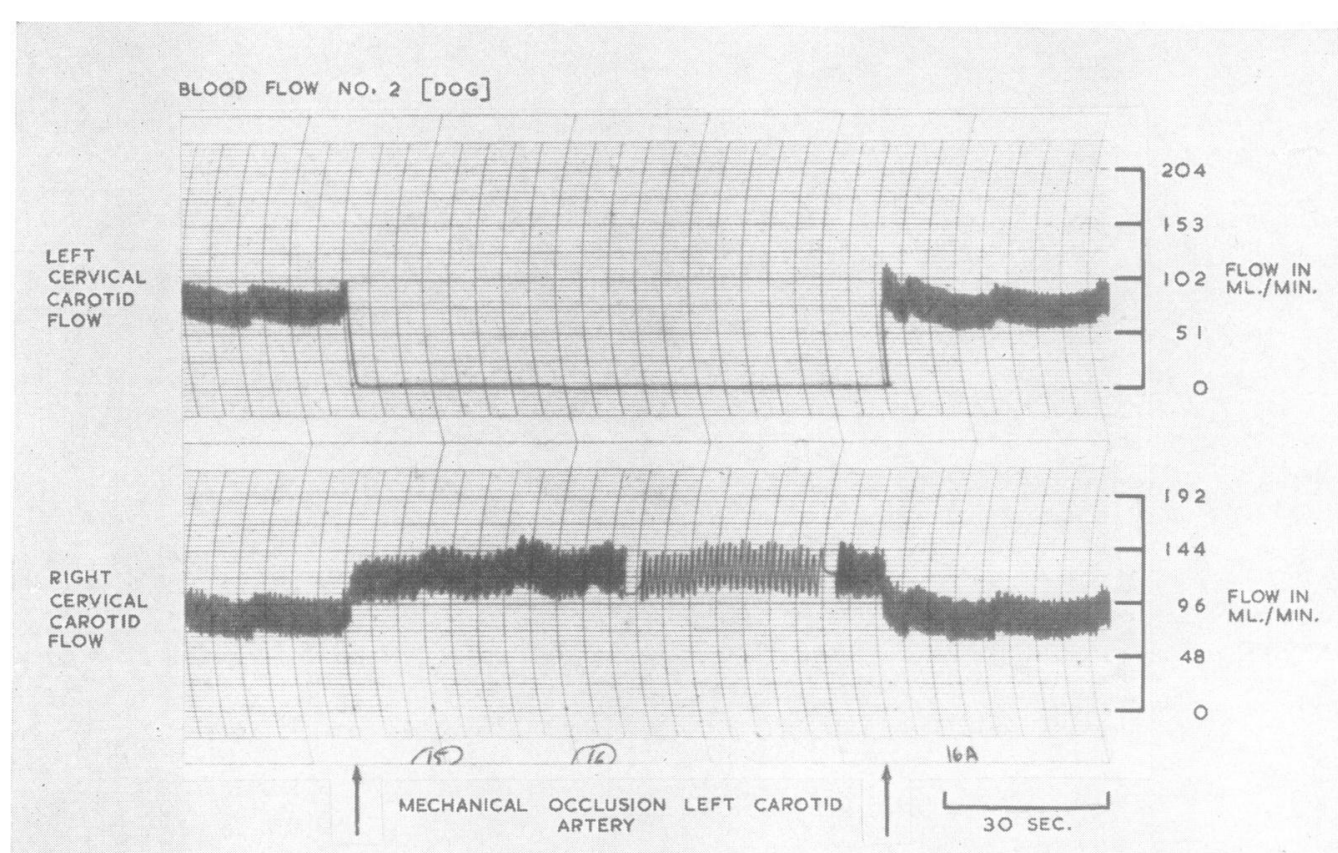

FIG. 1. Effect of left common carotid artery occlusion upon opposite blood flow in the dog. Note the superimposed respiratory effects, and the transient overshoot in flow of the left carotid upon its release from occlusion. 


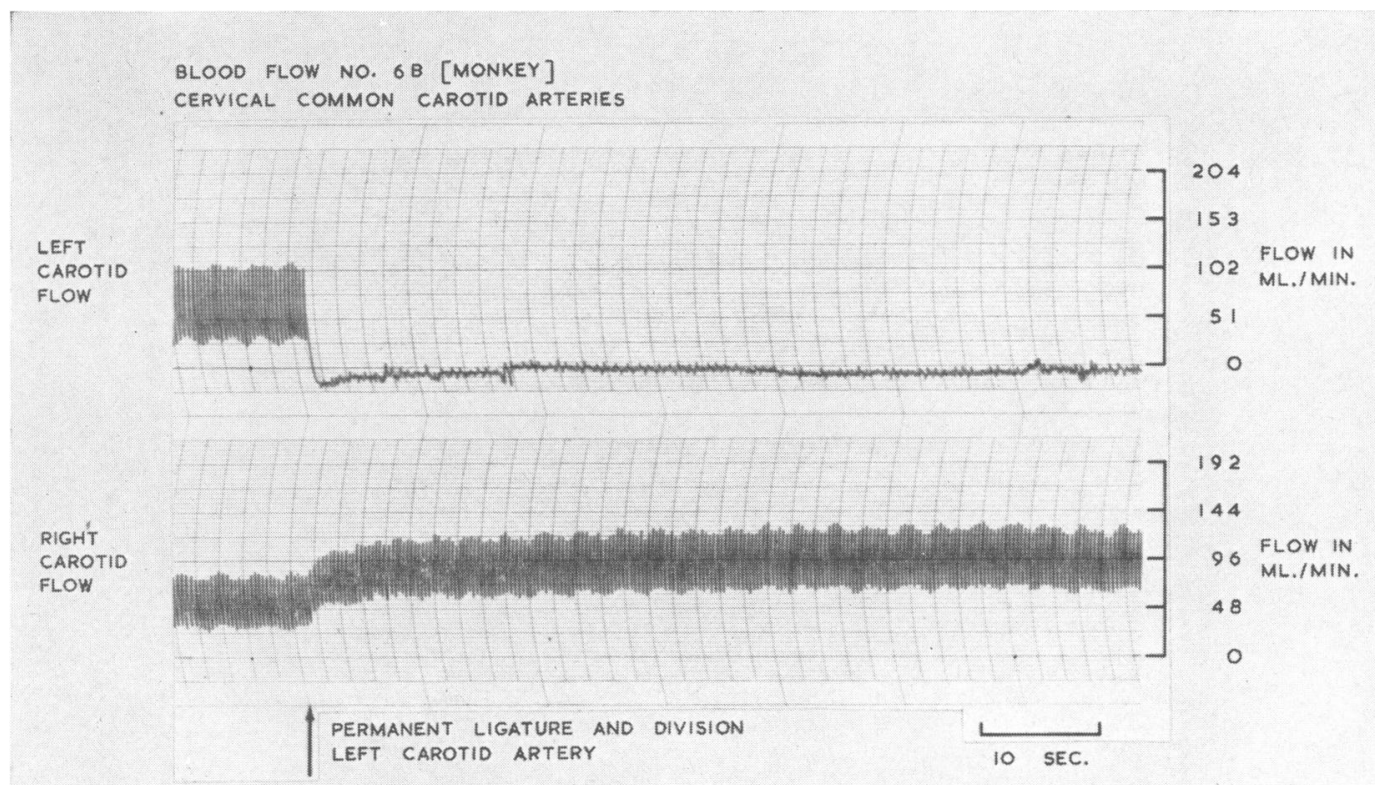

FIG. 2. Effect of left common carotid artery occlusion upon opposite carotid blood flow in the monkey.

then ligated at their sites of origin. Permanent leftsided carotid ligation was performed (Fig. 2). As can be seen the right-sided carotid flow almost doubled to a value of $101 \mathrm{ml} . / \mathrm{min}$. The animal was allowed to recover and did so without observable deficit, and six days later flow in this same artery was measured at $154 \mathrm{ml} . / \mathrm{min}$. with a mean femoral blood pressure of $137 \mathrm{~mm}$. Hg. It was evident that the increased flow which had been observed initially was not only sustained but had been further enhanced.

Commor carotid artery occlusion under the experimental circumstances outlined was associated with a rise in femoral arterial pressure. Figure 3 illustrates such a systemic blood pressure response. The cerebrospinal fluid pressure tracings seen in this figure indicate only a qualitative response to carotid artery occlusion and are given no quantitative interpretation. When both carotid arteries were occludzd sequentially the initial femoral arterial pressure rise was followe $d$ by a further rise seen as the second carotid artery was shut off (Fig. 4).

Upon the release of an occluded carotid artery the flow in this vessel would usually overshoot its preocclusion flow value, returning to its natural flow value in about 30 seconds. In the opposite carotid artery, flow which had been raised by the procedure, regularly $\mathrm{rcturned}$ to its preocclusion level as did the systemic arterial blood pressure (Figs. 3 and 4). In the circumstance of simultaneous bilateral carotid occlusion simultaneous release of both vessels was followed by a bilateral flow overshoot (Fig. 5).

In the one cat studied it was observed that unilateral femoral artery occlusion was associated with an increase in carotid flow and in contralateral femoral arterial pressure. It was further observed that anaesthetizing neighbouring pericarotid neural tissue locally in this animal did not obliterate the response of the contralateral carotid flow increase seen with unilateral carotid occlusion.

In the case of one monkey in hypovolaemic shock due to steady blood loss, no overshoot in ipsilateral carotid flow was observed when the artery was released from occlusion nor did any systemic blood pressure response occur, during or after carotid occlusion.

Examination of the structure of the circle of Willis in three of the animals which showed the contralateral carotid flow response established the presence of a normal pattern. In each instance the communication between the two sides of the anterior half of the circle was patent and appeared adequate in size.

AORTIC OCCLUSION Observations were made in two monkeys upon the flow changes in a single carotid artery after the opposite carotid vessel had been occluded and the subclavian arteries ligated proximal to the origins of the vertebral arteries. Figure 6 illustrates the effect of aortic cross-clamping distal to 


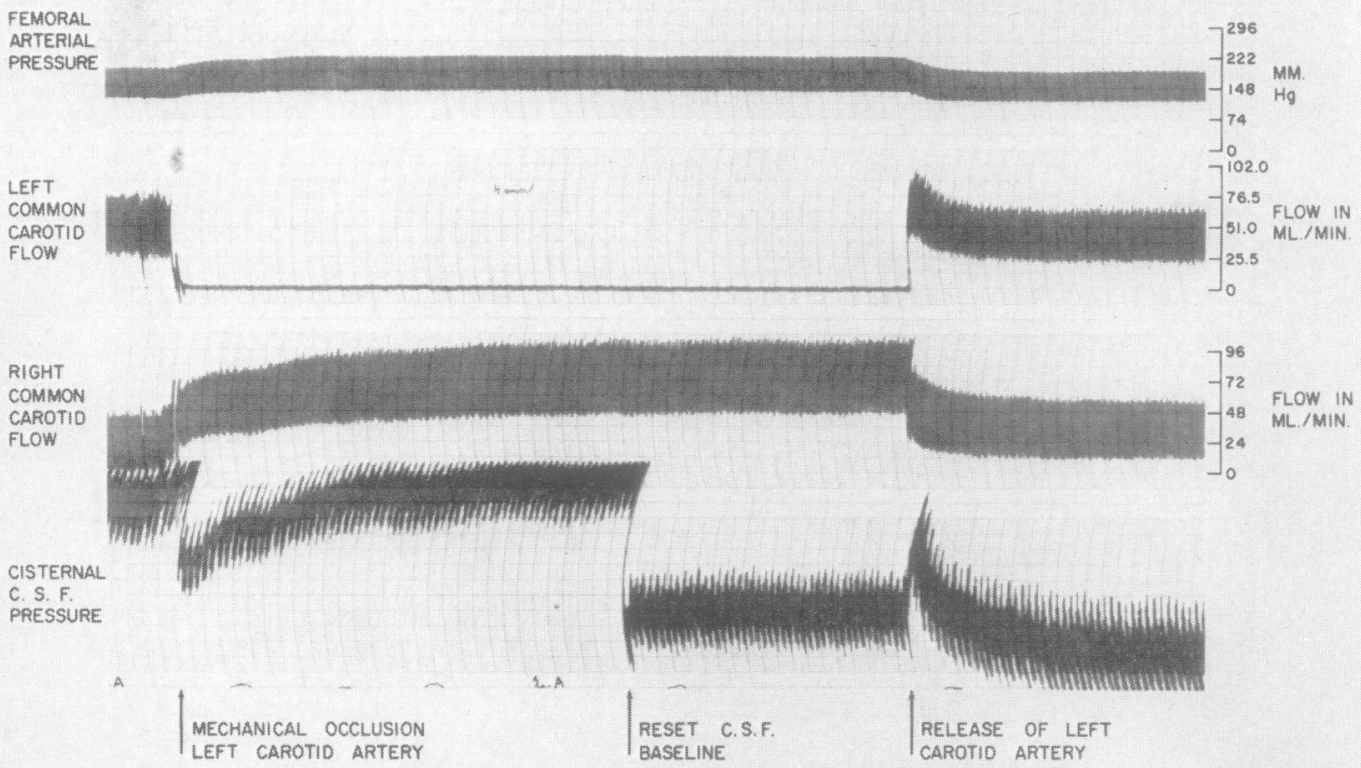

FIG. 3. Reproduction of the combined tracing in the monkey demonstrating the effect of unilateral carotid artery occlusion on contralateral carotid flow, femoral arterial blood pressure, and cisternal cerebrospinal fuid pressure. Note the overshoot in left carotid flow upon its release from occlusion.

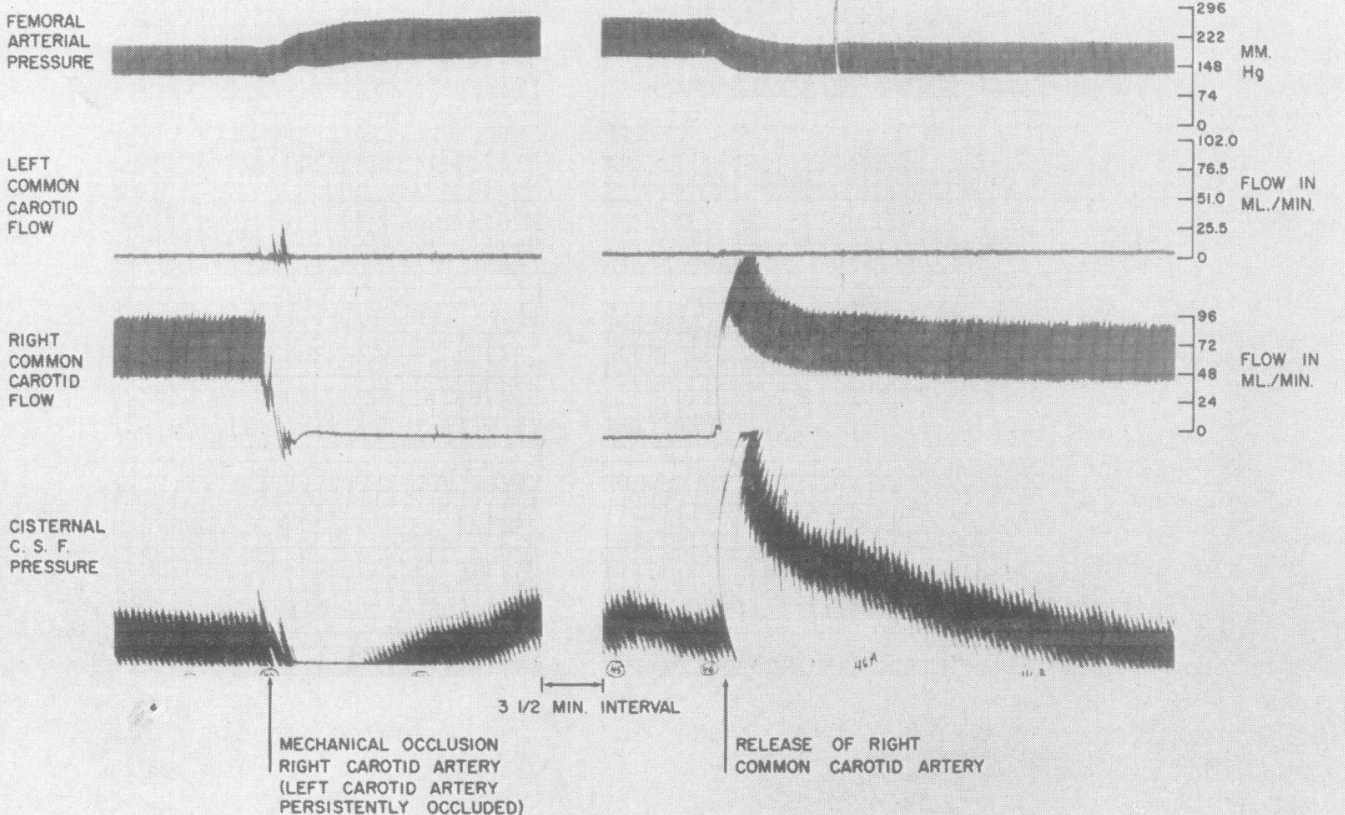

FIG. 4. Reproduction of the combined tracing in the same monkey as in Fig. 3 demonstrating the additive effect upon systemic femoral arterial and cerebrospinal fuid pressures of occluding the second carotid artery. Note that upon its release an overshoot exceeding that illustrated in Fig. 3 occurs. 


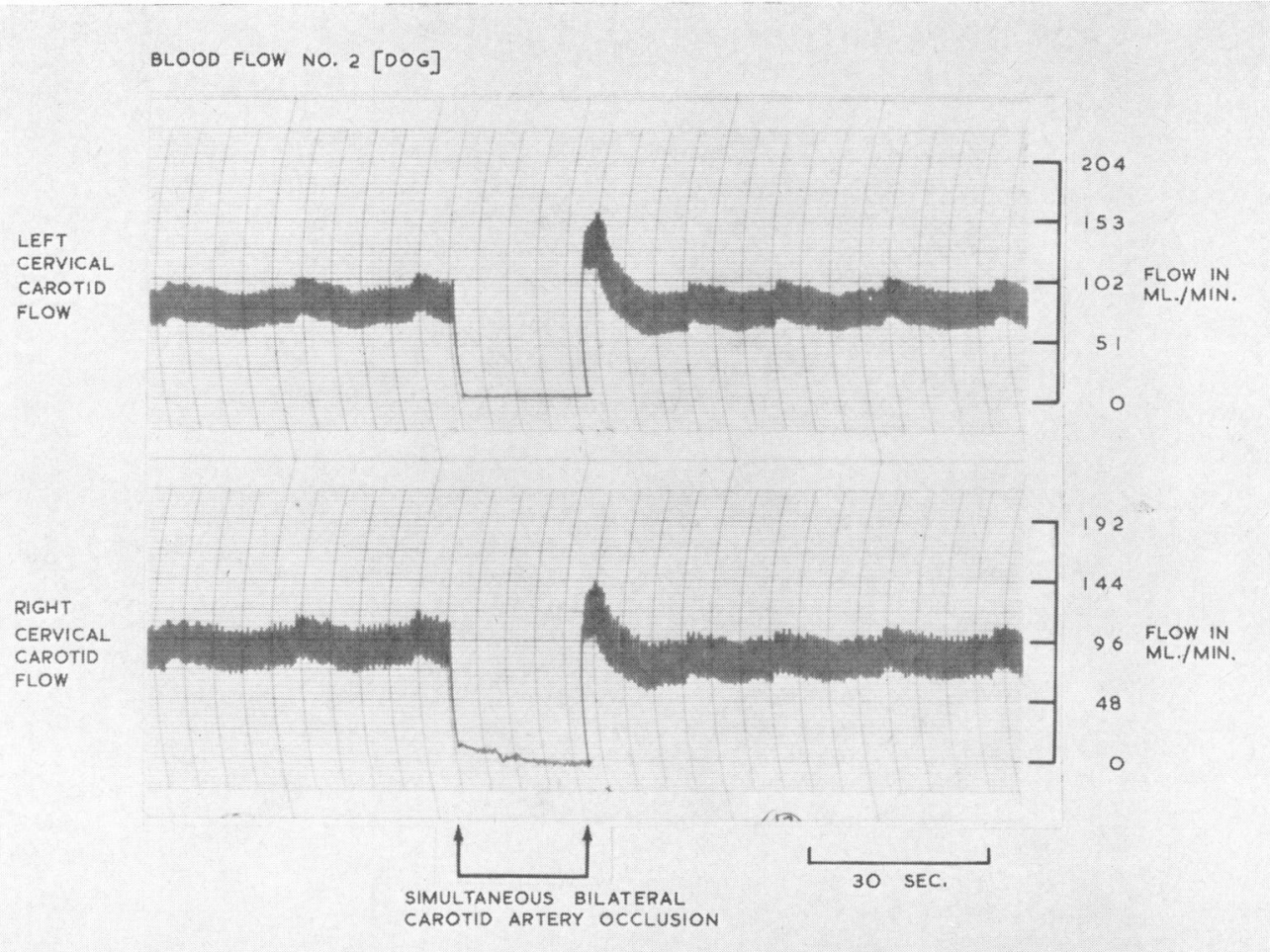

FIG. 5. The effect of simultaneous common carotid artery occlusion and release in the dog. Note the bilateral flow overshoot which occurred upon release.

the left subclavian artery in such an animal preparation. There was an obliteration of femoral blood pressure and a rise in carotid blood flow. The values for the percentage increase in carotid flow during occlusion of the aorta exceeded any similar values following other occlusive manoeuvres except for the transient overshoot occurring upon carotid release. When the aorta was released from its occlusion femoral arterial pressure reappeared, fell slightly, and then stabilized. It was notable that each time the aorta was released carotid flow fell to values below the pre-occlusion carotid flow values (Fig. 7). Such a fall was transient in each instance, and the carotid flow then returned to a stable pre-occlusion level.

CEREBROSPINAL FLUID RECORDINGS The cerebrospinal fluid pressures varied with changes in carotid blood flow as can be best seen in the accompanying figures. No numerical relationship can be given to these changes since the tracings were made in such a way to amplify maximally the cerebrospinal fluid pulse changes. Occlusion of the carotid arteries produced transient lowerings of the cerebrospinal fluid pressures and decreases in the amplitudes of cerebrospinal fluid pulse records. Release of occluded carotid vessels reversed these occurrences. Enhancement of carotid flow by aortic cross-clamping caused a transient rise in cerebrospinal fluid pressure and aortic release was associated with a fall in pressure, also transient. Because of technical difficulties of simultaneous recording in the production of the tracings illustrated no more quantitative interpretation than this seems justified. The tracings are reproduced untouched so as not to detract from the combined record.

\section{CAROTID STUDIES IN MAN}

CASE 1 The opportunity presented itself to record simultaneous bilateral flow from the internal carotid arteries of a 43-year-old woman suffering from a left sylvian arteriovenous malformation. Under general anaesthesia both internal carotid arteries were exposed, caution being taken to bathe the dissection field with $\frac{1}{2} \%$ xylocaine. The integrated flow values at a stable blood pressure were $275 \mathrm{ml} . / \mathrm{min}$. (left) and $150 \mathrm{ml} . / \mathrm{min}$. (right). 


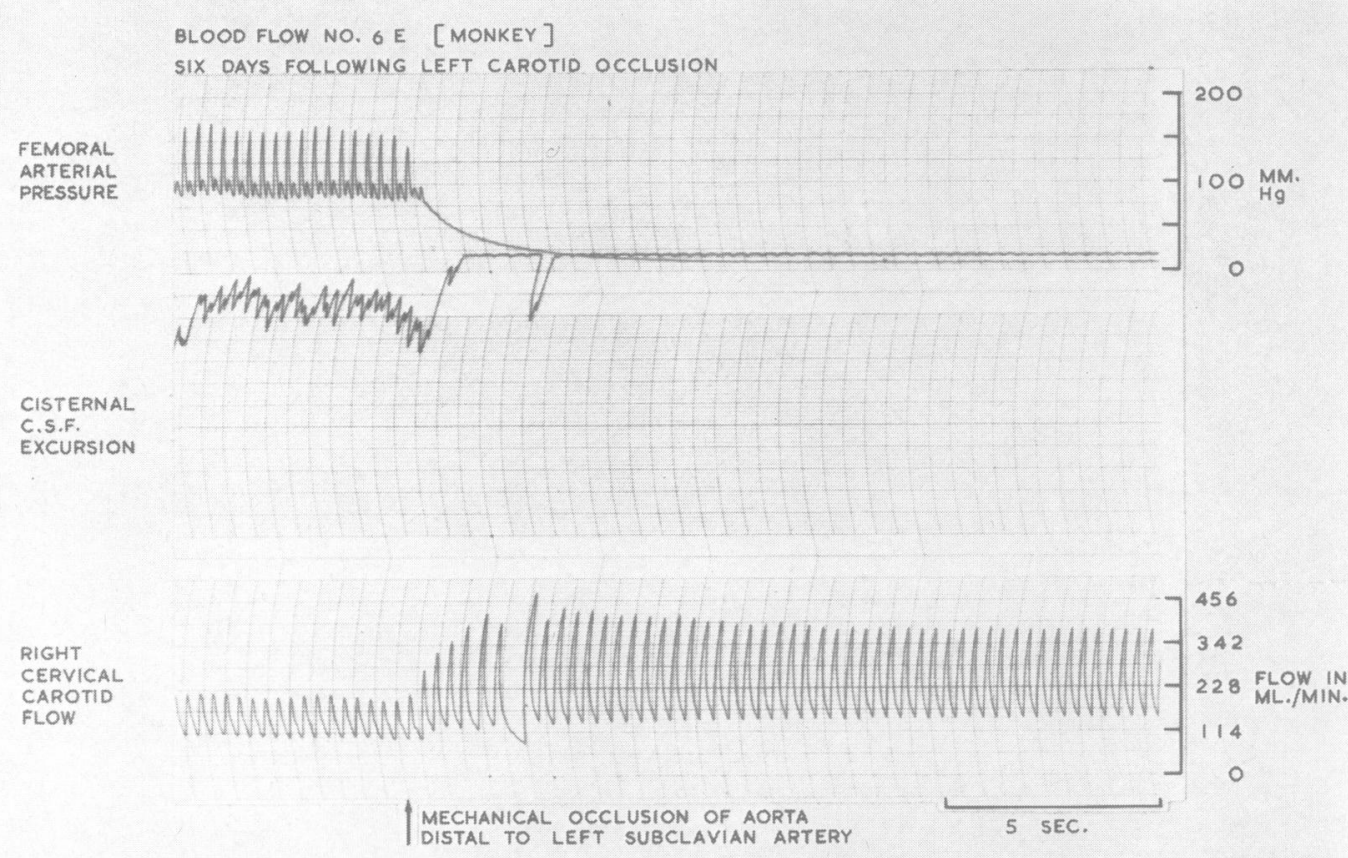

FIG. 6. Effects of aortic occlusion upon cervical carotid blood flow, femoral arterial blood pressure, and cisternal cerebrospinal fluid recordings after contralateral carotid artery ligation and bilateral vertebral and subclavian artery occlusion.

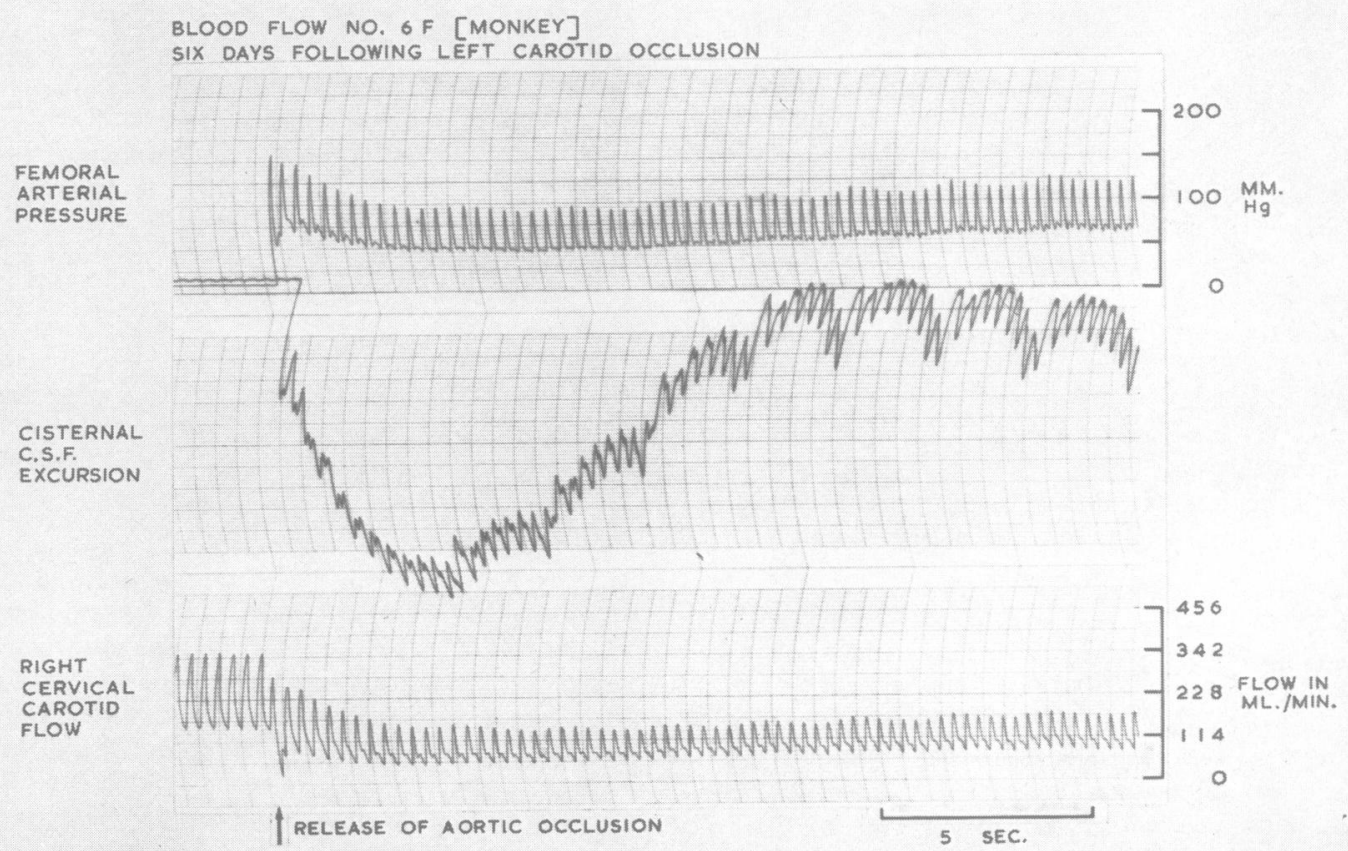

FIG. 7. Effects of aortic release upon carotid artery flow, femoral arterial blood pressure, and cisternal cerebrospinal pressure. The sequence of this tracing follows that of Fig. 6. 


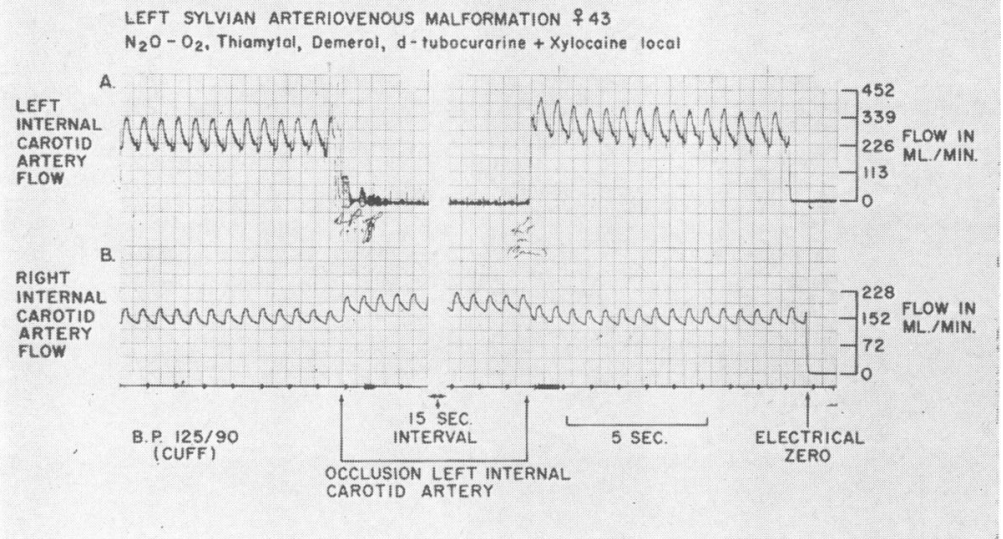

FIG. 8. Effects in man of internal carotid artery occlusion upon contralateral internal carotid flow in a patient (Case 1) with an intracranial vascular malformation. Note the wave form of the flow pulse and the overshoot in left internal carotid flow upon its release.

LEFT SYLVIAN ARTERIOVENOUS MALFORMATION $\$ 43$ $\mathrm{N}_{2} \mathrm{O}-\mathrm{O}_{2}$, Thiamytal, Demerol, d-fubocurarine +Xylocoine local

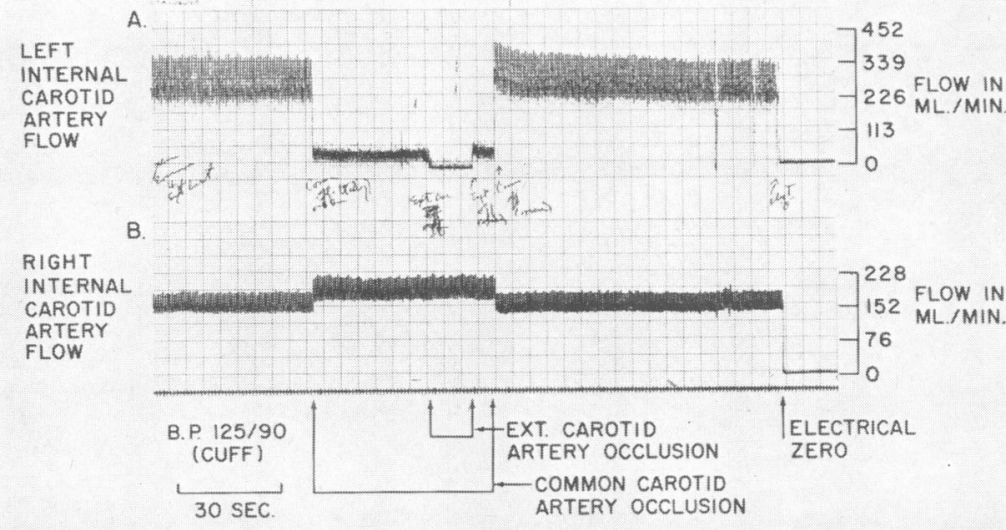

FIG. 9. Effects of common and external carotid artery occlusion upon ipsilateral and contralateral internal carotid artery flow in a patient with an intracranial vascular malformation (cf. Fig. 8).

Occlusion of the left internal carotid artery proximal to the flow probe produced a complete cessation of flow in this vessel and (similarly to the animals) a rise in flow in the opposite carotid artery (Fig. 8). The rise, however, was of smaller magnitude than that observed in the animals and represented only an $18 \%$ increase in the unilateral carotid flow in this patient. An overshoot above the pre-occlusion values in the flow of the vessel which had been occluded was noted on its release. Because of the observed increase in flow seen in the animals (and in this patient) the contralateral carotid artery was not occluded in respect of the diseased peripheral vascular bed. Common carotid artery occlusion produced a subtotal obliteration of flow which was then reduced to zero by superimposing external carotid occlusion, demonstrating that some flow, presumably external to internal, occurred during common carotid artery occlusion (Fig. 9).
CASE 2 A 24-year-old man was admitted to hospital having suffered a spontaneous subarachnoid haemorrhage from an aneurysm in the vicinity of the anterior communicating artery. In the pre-operative angiogram both anterior cerebral arteries filled from the left side only and the large aneurysm filled from the left injection. One-half centimetre of the proximal anterior cerebral artery filled from the right injection even with contralateral carotid compression. At the time of craniotomy on 28 April 1961 both the aneurysmal neck and the anterior communicating artery were clipped. No clips remained on the anterior cerebral arteries. This procedure effectively isolated one from the other of the two anterior halves of the circle of Willis. This isolation was confirmed post-operatively by angiography in which each carotid injection demonstrated complete ipsilateral middle and anterior cerebral artery filling without cross-over from either side (Fig. 10). 

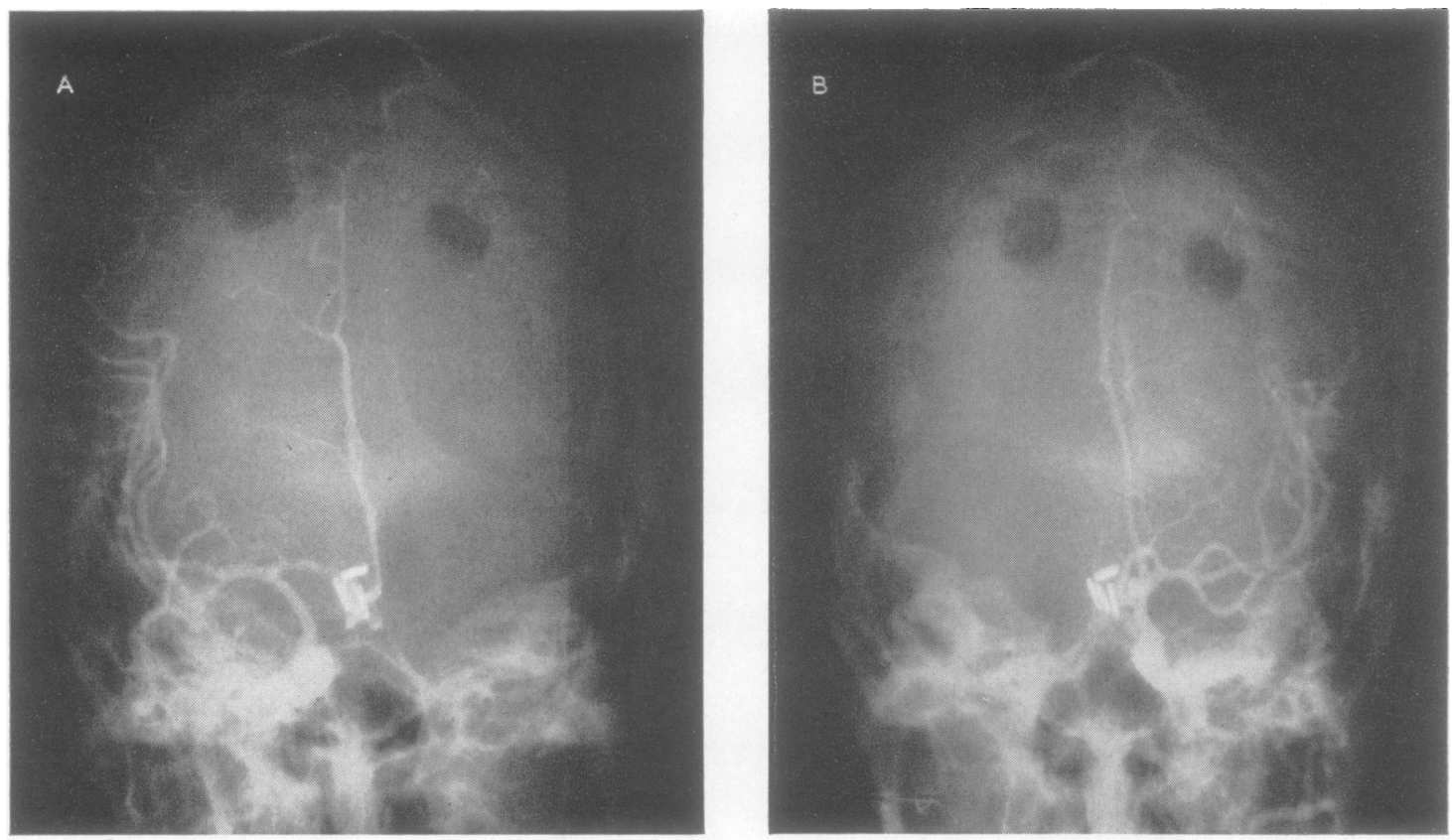

FIG. 10. Post-craniotomy angiographic studies in Case 2 demonstrating the strict ipsilateral distribution of opaque material following right (A) and left (B) carotid artery injections.

A
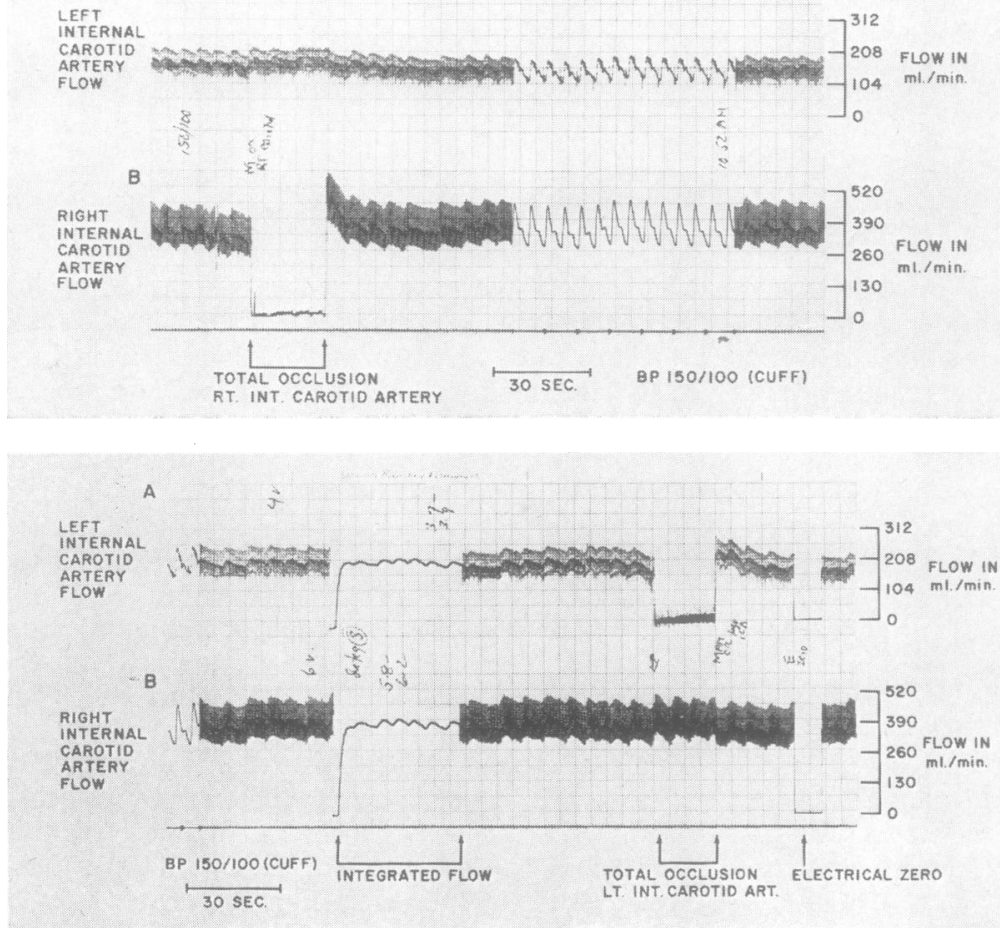

FIG. 11. Effects in man (Case 2) of right internal carotid artery occlusion upon left-sided flow.

Note the slight increase in left-sided flow during right-sided occlusion and the overshoot of the flow of the occluded artery upon its release. Note the flow pulse wave form.

FIG. 12. Left internal carotid artery occlusion in Case 2 (cf. Fig. 11). 
Bilateral internal carotid artery flow studies were then made on 25 May 1961. The same techniques of anaesthesia were employed as in the first patient. At a stable brachial blood pressure of $150 / 100 \mathrm{~mm}$. Hg the left carotid flow ranged from 187 to $208 \mathrm{ml} . / \mathrm{min}$. and the right carotid flow between 377 and $416 \mathrm{ml}$./ min. These values would provide a combined carotid flow of from 564 to $624 \mathrm{ml} . / \mathrm{min}$. Calculated on the assumption that the internal carotid arteries carry approximately $70 \%$ of total cerebral blood flow, the latter would be 805 to $891 \mathrm{ml} . / \mathrm{min}$. When the right internal carotid artery was occluded, flow through the left rose only slightly from a range of 187 to 208 to 208 to $228 \mathrm{ml}$./min., a mean rise of $5 \%$ (Fig. 11). When the left internal carotid artery was occluded, the right internal carotid flow values rose slightly from a range of 364 to 403 to 377 to $416 \mathrm{ml}$./min., a rise of about $3.5 \%$ (Fig. 12).

\section{DISCUSSION}

There are important differences between the animal studies and the studies in man: (a) the patients' recordings were made distal to the carotid bulb and involved the internal carotid arteries only; (b) local anaesthesia was added to general anaesthesia to aid in neutralizing carotid sinus effects; (c) it was known that the patients harboured arterial disease: an arteriovenous malformation in the left cerebral hemisphere, and an aneurysm which had been excluded from the circulation surgically. These obvious differences require cognisance in the interpretation of the data collected from such sources as animal and man, which differ in so many other ways as well.

The various methods employed to measure cerebral blood flow have their shortcomings. Direct observation of retinal or cortical vessels as studied by Cobb and Fremont-Smith (1931) and Wolff and Lennox (1930) permits a regional documentation of vessel size but no quantitative flow data. Relative changes in flow can be measured by utilizing the thermo-electric flow recorder as reported by Gibbs, Gibbs, and Lennox (1935). Ferris (1941) attempted to quantitate flow by measuring cerebrospinal fluid displacement after venous occlusion in the neck. His method produced values of 200 to $400 \mathrm{ml} . / \mathrm{min}$. blood flow in the brain of man.

Dumke and Schmidt (1943) and Schmidt, Kety, and Pennes (1945) found mean values of 60 to $47 \mathrm{ml}$./ $100 \mathrm{~g} . / \mathrm{min}$. in the Rhesus and Spider monkeys utilizing flow instruments incorporated as part of the arterial channels. Randall and Horvath (1953) reported mean unilateral common carotid flow values of from 96 to $112 \mathrm{ml}$./min. utilizing electric transducers inserted into the vessels. Chute and
Smyth (1939) reviewed the previous animal data obtained with stromuhrs and the information resulting from perfusion experiments and presented perfusion data for the cat suggesting a brain flow of 60 to $90 \mathrm{ml} . / 100 \mathrm{~g} . / \mathrm{min}$. (including the upper face and eyes). However, the limitations of perfusion techniques in providing reliable cerebral blood flow data have been emphasized by Geiger (1958). The data from the application of gaseous techniques employed by Kety and Schmidt (1948) were summarized by Kety in 1950. In man the value of $54 \mathrm{ml}$./ $100 \mathrm{~g} . / \mathrm{min}$. was considered the normal flow rate. In comparing the dye dilution method of Gibbs, Maxwell, and Gibbs (1947) with the nitrous oxide method, Shenkin, Harmel, and Kety (1948a) presented figures of $986 \mathrm{ml} . / \mathrm{min}$. and $756 \mathrm{ml} . / \mathrm{min}$. respectively for total cerebral blood flow in man for the two methods. The utilization of radioactive tracers in the form of Krypton ${ }^{85}$ by Munck and Lassen (1957) and $\mathrm{P}^{32}$ labelled erythrocytes by Nylin, Silverskiöld, Löfstedt, Regnström, and Hedlund (1960) has given comparable data. Data claimed to represent total cerebral blood flow in man by external counting techniques after the injection of Krypton ${ }^{79}$ have been presented by Lewis, Sokoloff, Wechsler, Wentz, and Kety (1960) who gave $1,236 \mathrm{ml} . / \mathrm{min}$. as a mean value.

CAROTID OCCLUSION OBSERVATIONS In reviewing the data collected by Sweet and Bennett (1948), Sweet, Sarnoff, and Bakay (1950) and Brackett and Mount (1951), the latter investigators recorded a case in which both internal carotid arteries were catheterized; a rise in the contralateral vessel pressure from $132 / 80 \mathrm{~mm}$. $\mathrm{Hg}$ to $180 / 114 \mathrm{~mm}$. $\mathrm{Hg}$ occurred as the ipsilateral pressure fell with compression from $147 / 90 \mathrm{~mm}$. Hg to $40 / 37 \mathrm{~mm}$. Hg. It was Pearse (1928), taking his cue from Mall (1896), who found that in dogs with major arterial ligation a proximal blood pressure rise occurred. If one common carotid artery were occluded the pressure in the opposite carotid artery rose. The same reciprocal relationship also held between the two femoral arteries. Pearse concluded that if proximal pressure were raised it might forcibly dilate collateral channels and maintain the viability of peripheral parts. Nowak and Walker (1939) noted the effects of interference with the carotid sinus innervation and aortic depressor nerves in the production of arterial hypertension in dogs, and produced hypertension by ligating cerebral vessels. In the present animal work the blood pressure response to carotid occlusion is expected and explained by the operation of the carotid sinus mechanism. Pearse's experience suggests, however, that such a pressure rise is not peculiar to occlusion of the carotid system and, therefore, requires some 
additional explanation other than the involvement of the carotid sinus mechanism. Polosa and Rossi (1961) review possible mechanisms of the pressor effect of carotid occlusion. They note the evidence favouring an increase in cardiac output and contrast this with evidence supporting an increase in peripheral vascular resistance. Utilizing dogs these workers found that bilateral common carotid artery occlusion was associated with a variable response in femoral blood flow but always an increase in peripheral vascular resistance. A similar increase in peripheral vascular resistance was observed in the kidney and splanchnic areas. Carotid output, measured by the pulse contour or electromagnetic flowmeter methods, was not increased. No unilateral carotid occlusion studies were reported nor were carotid flow studies included, but it would appear that whatever may have explained these workers' findings on the peripheral blood flow it would seem to conflict with the present data in so far as the carotid bed itself is concerned. An increase in peripheral vascular resistance in the intact carotid system was definitely not supported by the data of enhanced flow during contralateral carotid occlusion. Of timely interest is the recent work of Hardesty, Roberts, Toole, and Royster (1961) who employed the electromagnetic flow principle (but with different instruments from those employed in the present work) to study internal carotid artery flow in patients undergoing radical neck procedures. The mean internal carotid flow was found to be $364 \mathrm{ml}$./ min. in 11 patients. With contralateral-carotid compression (usually percutaneous) flow increases of from 13 to $38 \%$ were recorded. Although flow through a single vessel only was measured at any one time, these authors estimated the bilateral internal carotid supply to comprise two-thirds of total brain blood flow, with the figure for the latter therefore estimated at $1,090 \mathrm{ml} / / \mathrm{min}$. They suggested that the increase in flow in one carotid artery when the opposite is occluded was primarily mechanical and resulted from a drop in arterial pressure in one hemisphere. It could be assumed that what these workers propose is that the decreased resistance in the cerebral vascular bed which results from the fall in blood volume attendant upon occlusion permits a greater volume to be thrust through the remaining channels in a given time period and at the same pressure head.

If this were to be the case then the amount of increase in flow in such circumstances may well be related in part, at least, to the size and adequacy of the cross-over channels between the two halves of the anterior portion of the circle of Willis and the size and adequacy of the channels connecting the anterior and posterior halves of the circle. A study of the relationship between carotid artery pressures during occlusion and radiological evidence of bilateral and anterior-posterior communication was reported by Stern (1953).

In the circumstance of the patient harbouring the arteriovenous malformation our records were of internal carotid flow only and were, therefore, more significant than the information from the animal studies in which much of the measured supply was destined for extracranial tissues of the head. From the angiographic studies it was seen that the right side of the circulation readily communicated with the diseased side. The greater flow on the side of the malformation probably reflects the decreased resistance of the peripheral bed, a concept supported by the pertinent observations of Shenkin, Spitz, Grant, and Kety (1948b). The increase in flow in the right internal carotid artery with left-sided occlusion did not approximate, in percentage terms, that seen in the animal work. The same may be said of the second patient studied. The relative size of the vascular beds which are influenced by the occlusion may explain these differences of degree between animal and man, but it is to be emphasized that the animal records were of common carotid flow while in man only the internal carotid flow was measured and local anaesthetization about the carotid sinus was utilized.

The data from the second patient, however, coincide with the prediction that the presence of a defective circle of Willis, especially a defective channel between the two anterior halves of the circle, would be associated with less of an increase in flow in the carotid artery with opposite occlusion than if the circle incorporated wide anterior-communicating channels.

Against the background of the foregoing discussion there are the following findings to consider: (a) Carotid flow overshoot upon the release of an occluded artery; (b) contralateral flow increase with ipsilateral carotid artery occlusion; (c) the findings associated with aortic occlusion, especially the transient fall in carotid flow below the pre-occlusion values when the aorta is released; (d) the absence of carotid flow overshoot or femoral pressure response in the state of hypovolaemic shock.

The mechanisms at work to explain these data are undoubtedly several and closely interrelated.

(a) CAROTID OVERSHOOT ON RELEASE OF OCCLUSIONS When a carotid artery is occluded there is a reduction of blood bulk and pressure and resistance within its territory. Such a reduction may encourage the inflow of blood from other neighbouring feeding channels. As the carotid artery is released from compression carotid flow momentarily rises above 
pre-occlusion levels; the vascular bed distal to the occlusion site seems to accept a greater volume on the basis of a transiently decreased resistance. Although the Starling phenomenon may also be operative it may be argued that the depleted bed offers less impedance to rapid filling, but subsequently the filled vessels offer increasing resistance reflected in the fall of carotid flow to normal following its initial overshoot. This response has been well described in the dog by Randall and Horvath (loc. cit.) who credit Lewis and Grant (1925) with the introduction of the concept of reactive hypaemia following ischaemia in the distribution of a single artery. Randall and Horvath, however, do not consider the filling of an empty, low-resistance bed the major mechanism for the transient flow increase seen after occlusion of a vessel. They support the concept of vasodilatation produced by accumulated metabolites incident to the preceding ischaemia. Inouye and Kosaka (1959), using dogs and rabbits, report a similar phenomenon after carotid and femoral artery occlusion. In their study of patterns of pulsatile flow utilizing the electromagnetic flowmeter these workers found the increased flow pulse preceded the increase in pressure pulse. My data cannot ascribe relative importance to the roles of the two proposed mechanisms for the transient rise in flow seen after artery release, but the importance of the mechanically emptied vascular bed in decreasing resistance does not appear lessened.

(b) CONTRALATERAL INCREASE IN FLOW It may be reasoned that if the communications are large between the bed of supply of the occluded artery and neighbouring arterial channels then the resistance afforded to blood flow in such a neighbouring system would be decreased and reflected in an augmented flow through the major feeding arteries thereof. Particularly would this be true if all but one feeding channel into a common vascular network were occluded. This situation was approximated in the animal experiments in which the vertebral arteries were ligated. Unilateral carotid occlusion was followed by a $75 \%$ or more increase in flow in the remaining patent carotid artery. If, contrariwise, there were to be a lack of anatomical communication of significant size between the neighbouring vascular bed and the bed which is deprived of blood by occlusion there might be expected to be a slight increase only in the flow through the feeding arteries of the neighbouring area. Such was the finding in the unusual circumstance of surgical isolation of the two anterior halves of the circle of Willis. Control flow data in this case are admittedly lacking.

(c) FLOW FALL AFTER AORTIC COMPRESSION RELEASE Another aspect to consider in explaining certain of the observed phenomena is the volumetric relationship between various vascular beds in the body. Quite apart from the role of the carotid sinus mechanism in augmenting systemic pressure when carotid occlusion is produced there is the fact that more blood is available for other vascular beds when one area is deprived of its volume by occlusion. The proximal vascular bed promptly responds to the abruptly added volume of blood otherwise destined for the head. The reverse situation exists when the aorta is occluded; carotid flow is strikingly increased. Further validity is given to such a 'redistribuiion effect' by the evidence of 'bleeding' of the carotid system, that is to say, the fall below preocclusion levels of carotid flow which occurs when the aorta is released from its cross clamping. It appears that the sudden opening up of a lowresistance, extra-carotid vascular bed momentarily robs the carotid system of its usual flow.

(d) LACK OF RESPONSES IN THE HYPOVOLAEMIC STATE The mere absence of adequate volumes of blood for redistribution in a depleted series of vascular beds is an appealing argument but evidence from this study is inadequate to defend this view.

\section{SUMMARY}

The electromagnetic flow principle has been applied to a study of cervical carotid blood flow in animal and man.

The values of carotid blood flow in animal and man obtained with electromagnetic flowmeters are of the same order of magnitude as reported in other investigations.

There is a significant increase in carotid flow when the contralateral carotid artery is occluded.

Variations in the carotid flow which are seen following the release of ipsilateral carotid artery occlusion or aortic occlusion support the concept of transient changes in peripheral resistance. One vascular bed bleeds into another.

The effects upon systemic blood pressure and carotid flow when various vessels are occluded lend support to the concept of a redistribution effect upon pressure when blood is redirected from one vascular bed to another as resistance alters. A reciprocal effect is seen upon the pressure in the bed from which the blood is shunted.

Evidence is presented to suggest that the usual effects of carotid compression upon contralateral carotid flow are dampened significantly in the face of defective communication between both sides of the anterior half of the circle of Willis. The potential recipient vascular bed is reduced by the structural defect. 
These observations shed light upon and pose new questions about the interdependence of the cerebral and systemic arterial circulations.

I gratefully acknowledge the technical assistance of Messrs. Allen Westersten and George Herrold whose design of the electromagnetic flowmeters was utilized. I also wish to thank Dr. Nicholas Assali, Professor of Obstetrics and Gynecology in the University of California, for his generosity in making flowmeter equipment available from his laboratory in the early phases of this study.

\section{REFERENCES}

Brackett, C. E., and Mount, L. A. (1951). Surg. For. 1950, p. 344. Saunders, Philadelphia.

Chute, A. L., and Smyth, D. H. (1939). Quart. J. exp. Physiol., 29, 379.

Cobb, S., and Fremont-Smith, F. (1931). Arch. Neurol. Psychiat. (Chic.), 26, 731 .

Dumke, P. R., and Schmidt, C. F. (1943). Amer. J. Physiol., 138, 421.

Ferris E. B. (1941). Arch. Neurol. Psychiat. (Chic.), 46, 377.

Geiger, A. (1958). Physiol Rev., 38, 1.

Gibbs, F. A., Gibbs, E. L., and Lennox, W. G. (1935). Amer. J. Physiol., 111, 557.

-, Maxwell, H., and Gibbs, E. L. (1947). Arch. Neurol. Psychiat. (Chic.), 57, 137.
Hardesty, W. H., Roberts, B., Toole, J. F., and Royster, H. P. (1961). Surgery, 49, 251.

Inouye, A., and Kosaka, H. (1959). J. Physiol., 147, 209.

Kety, S. S. (1950). Amer. J. Med., 8, 205.

- and Schmidt, C. F. (1948). J. clin. Invest., 27, 476.

Kolin, A. (1936). Proc. Soc. exp. Biol. (N.Y.), 35, 53.

Lewis, T., and Grant, R. (1925). Heart, 12, 73.

Lewis, B. M., Sokoloff, L., Wechsler, R. L., Wentz, W. B., and Kety, S. S. (1960). J. clin. Invest., 39, 707.

Mall, F. P. (1896). Johns Hopk. Hosp. Rep., 1, 111.

Munck, O., and Lassen, N. A. (1957). Circulat. Res., 5, 163.

Nowak, S. J. G., and Walker, I. J. (1939). New Engl. J. Med., 220, 269.

Nylin, G., Silverskiöld, B. P., Löfstedt, S., Regnström, O., and Hedlund, S. (1960), Brain, 83, 293.

Pearse, H. E., Jr. (1928). Amer. J. med. Sci., Ser. 2, 175, 49.

Polosa, C., and Rossi, G. (1961). Amer. J. Physiol., 200, 1185.

Randall, J. F., and Horvath, S. M. (1953). Ibid., 172, 391.

Richards, T. G., and Williams, T. D. (1953). J. Physiol., 120, 257.

Schmidt, C. F., Kety, S. S., and Pennes, H. H. (1945). Amer. J. Physiol., 143, 33.

Shenkin, H. A., Harmel, M. H., and Kety, S. S. (1948a). Arch. Neurol. Psychiat. (Chic.), 60, 240.

_, Spitz, E. B., Grant, F. C., and Kety, S. S. (1948b). J. Neurosurg., 5,165 .

Stern, W. E. (1953). Ibid., 10, 577.

Sweet, W. H., and Bennett, H. S. (1948). Ibid., 5, 178.

-, Sarnoff, S. J., and Bakay, L. (1950). Surg. Gynec. Obstet., 90, 327.

Westersten, A., Herrold, G., and Assali, N. S. (1960). J. appl. Physiol., $15,533$.

Wolff, H. G., and Lennox, W. G. (1930). Arch. Neurol. Psychiat. (Chic.), 23, 1097. 